\title{
Piecewise Modelling Approach for Specific Switched Reluctance Machines
}

\author{
Ganeish Velmurugan, Seang Shen Yeoh, Tao Yang, Serhiy Bozhko \\ Department of Electrical and Electronic Engineering, University of Nottingham, UK \\ ganeish.velmurugan@nottingham.ac.uk
}

\begin{abstract}
Switched Reluctance Machine (SRM) is a very basic and simple electrical machine in structure with winding only at its stator. SRM has widely been considered for possible usages in modern aircrafts through the development of More Electric Aircraft (MEA). However, the nonlinear behavior of SRM results in difficulty in obtaining accurate model for simulation and development of its control system. A piecewise analytical modelling using inductance profile for a specific SRM is presented in this paper. The SRM used in this study is a specific custom designed $45 \mathrm{~kW}$ 6/4 SRM which has unique electromagnetic characteristics. In this paper, the analytical model presented is compared against the measured values for accuracy.
\end{abstract}

Keywords-Switched Reluctance Machine, Analytical modelling, More Electric Aircraft

\section{INTRODUCTION}

SRM is one of the earliest electrical machine developed dating back to $19^{\text {th }}$ century [1]. In recent times however, SRM has been gaining a lot of research interest including potential usages in aircrafts. Development towards More Electric Aircraft (MEA) has increased the need for more electrical power on-board aircrafts. One of the key enablers of development towards MEA is the starter/generator $(\mathrm{S} / \mathrm{G})$ technology. $\mathrm{S} / \mathrm{G}$ technology enables a single electrical machine to operate in motoring (starter) and generation modes on demand. Electrical machine operation in aircraft requires reliability and high fault tolerant to be able for operation in high speed, high temperature and harsh environmental conditions. As such SRM has been widely researched as a potential candidate as $\mathrm{S} / \mathrm{G}$ in aircraft.

Due to the nature of construction of SRM where it does not have any permanent magnets and copper windings only on its stator, it is an attractive choice to be considered as $\mathrm{S} / \mathrm{G}$ in aircraft. The lack of permanent magnet allows the machine to operate in harsh environmental condition and requires much simpler cooling system [2]. The simpler cooling system also reduces the overall weight of the $\mathrm{S} / \mathrm{G}$ which is a major objective in MEA development. These properties of the SRM are attractive for potential usage in MEA which requires high reliability and ability to operate in harsh environmental conditions [3].

However, the physical geometry of the SRM causes some disadvantages. SRM has salient poles in both its stator and rotor poles. This results in a highly non-linear magnetic characteristics. SRMs are operated in the heavy magnetic saturation in order to produce large ratio of torque to mass [4]. The high nonlinearities complicates the analysis and control of the SRM drives. Commonly used linear analytical modelling cannot be used for SRM as it needs to take into consideration of the nonlinear magnetization characteristics. In high speed operation such as in aircraft, it is vital to be able to have an accurate software model in order to reduce expensive and time consuming hardware development [5]. Thus, it is important to have an accurate analytical model of SRM for accurate control development in simulation environment.

Various analytical modelling of SRM has been presented in literature. One of the earliest analytical model of SRM was presented by Torrey in [6]. The paper presents analytical modelling of the magnetization characteristics using piecewise linear modelling. Geometry based analytical was presented in [7] which presents a new analytical representation of the SRM flux linkage as a function of current and rotor position while taking into consideration of magnetic saturation. The analytical representation is approximated by Fourier series representation. In [8], a versatile nonlinear SRM model is presented by utilizing the magnetization characteristics obtained through experimental measurements. The analytical model is then derived using the electromagnetic equations of SRM. In [9], a numerical method based selftraining of SRM magnetic characteristics are presented. Despite the initial overhead for the training algorithm, the proposed technique provides a very accurate analytical model. An analytical modelling that utilizes techniques presented in [8] and [7] is presented in [10] for deeply saturated SRMs. The presented model is developed using magnetization characteristic data which is then represented using an improved Fourier series for deeply saturated machine.

In this paper, an analytical model of a specific custom designed $45 \mathrm{~kW} 6 / 4$ SRM developed by [11] is presented. The SRM used for this study is unlike standard SRM where it has cavity in the rotor poles. This also results in magnetic characteristic that is unlike standard SRMs. Fig. 1 illustrates a generic SRM geometry and the SRM used for the study in this paper.

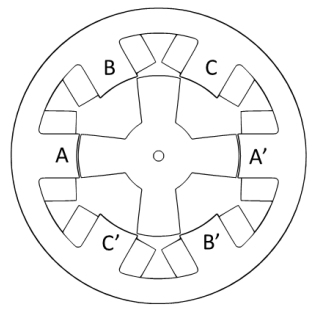

(a)

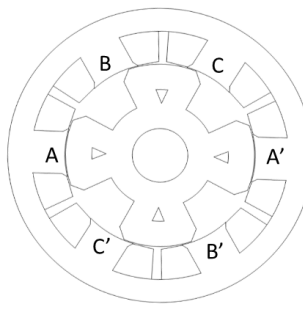

(b)
Fig. 1 : (a) Standard 6/4 SRM structure, (b) Custom designed 6/4 SRM

Due to the unconventional SRM geometry design used, a new analytical modelling approach is required for this machine. In this paper, a piecewise analytical model is presented to represent the magnetic properties of the 
SRM. The analytical model is derived by first deriving the analytical model to describe the inductance behavior. The paper is organized as follows: Section II lists basic fundamental concept of SRM's electromagnetic properties. In Section III, the analytical model using piecewise analysis is presented. Finally in Section IV, error analysis of the analytical model to its measured model is presented.

\section{SRM FUNDAMENTALS}

Electromagnetic properties such as inductance and torque can be derived from the magnetization characteristics. The magnetization characteristic can be obtained through experimental measurement or using Finite Element Analysis (FEA) tools. Fig. 2 shows the magnetization characteristics for the SRM used for the study in this paper.

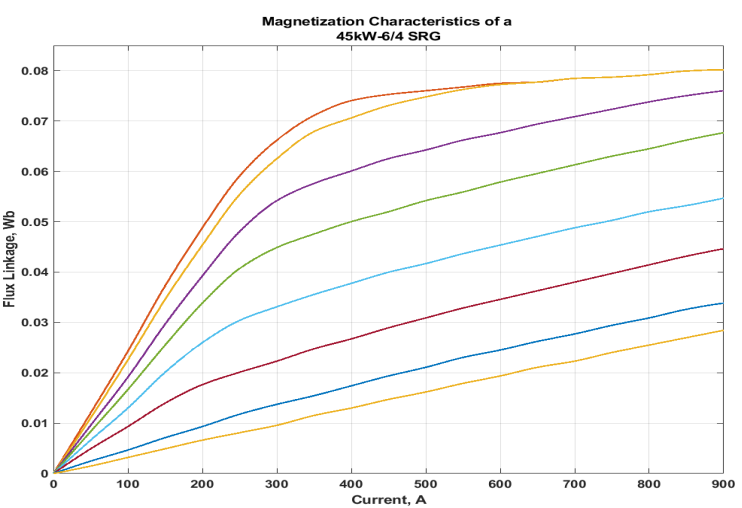

Fig. 2 Magnetization Characteristics of studied SRM

The magnetization characteristics in Fig. 2 describes flux linkage behavior to the rotor angle position of machine for different current operating region. Inductance profile of the SRM can be calculated using the magnetization characteristics. Relationship between flux linkage, $\lambda$ and inductance, $L$ is defined as,

$$
\lambda(\theta, i)=L(\theta, i) i
$$

The inductance, $L(i, \theta)$ can then be found as,

$$
L(\theta, i)=\lambda(\theta, i) / i
$$

Using the magnetization characteristic from Fig. 2, the inductance profile is then calculated using eq (2). Fig. 3 shows the inductance profile for studied SRM.

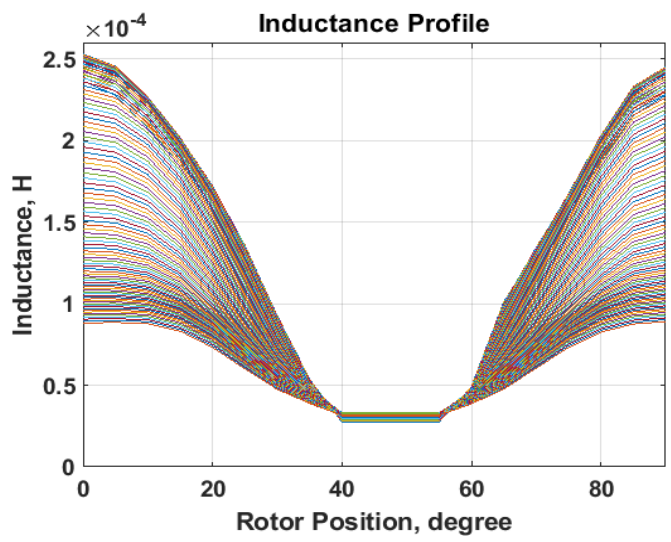

Fig. 3 Inductance Profile derived from Magnetization Characteristics
Next, the electromagnetic torque needs to be calculated. Electromagnetic torque produced in SRM is expressed in terms of magnetic co-energy, $W_{c}$ as:

$$
T=\left.\frac{\partial W_{C}(\theta, i)}{\partial \theta}\right|_{i=c o n s}
$$

Magnetic co-energy, $W_{c}$ can actually be calculated from the magnetization characteristics from Fig. 2 and is defined as,

$$
W_{C}(\theta, i)=\int_{0}^{i} \lambda(\theta, i) d i
$$

Using definition of flux linkage in eq (1) and replacing into eq (3) and (4), the electromagnetic torque, $T$ is then formulated as,

$$
T \cong \frac{1}{2} i^{2} \frac{\partial L}{\partial \theta}
$$

Using these equations, the torque profile can then be found as shown in Fig. 4

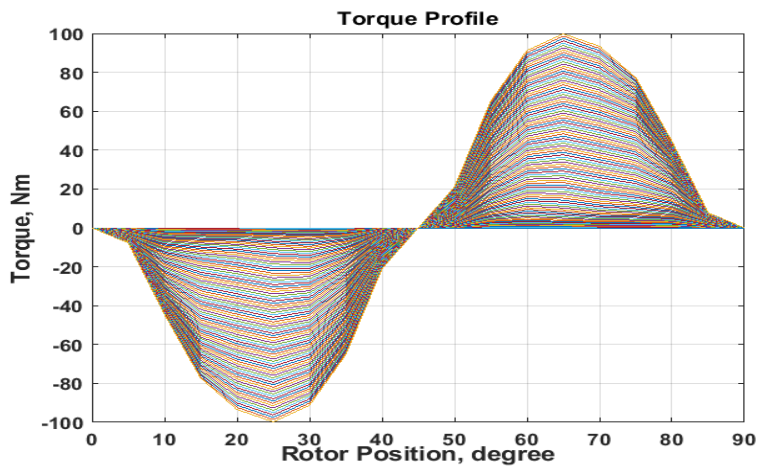

Fig. 4 Calculated Torque Profile

\section{ANALYTICAL MODELLING}

\section{A. Inductance Modelling}

From the electromagnetic behavior seen in Fig. 2 and Fig. 3, analytical model then must be derived as accurately as possible in order for accurate design of SRM control in the simulation environment. A piecewise analytical modelling technique is presented in this paper. Analytical equations are defined to model the inductance profile behavior. Using the inductance profile model, electromagnetic properties such as flux linkage and torque can be derived.

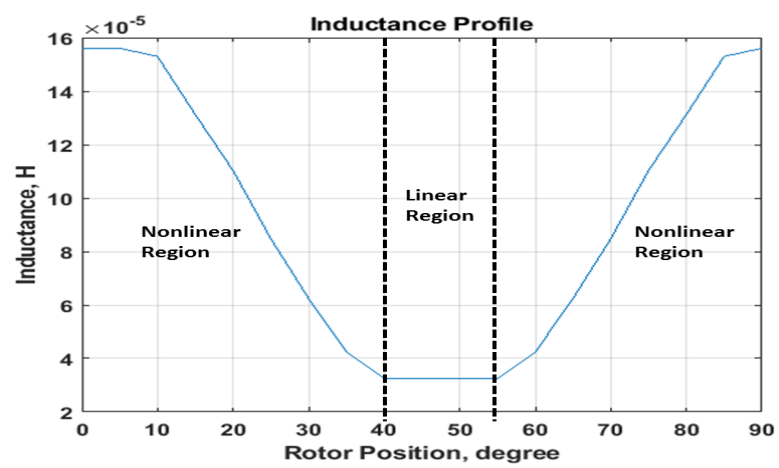

Fig. 5 Illustration of linear and nonlinear region in inductance profile 
From Fig. 5, it can be observed that the inductance profile has a region where the behavior is linear. The linear behavior is seen at rotor position from 35 to 55 degrees. The linear and nonlinear region can be represented analytically through a piecewise method.

\section{1) Nonlinear Region Analytical Model}

The nonlinear region of the inductance can be seen from rotor position, $\theta_{r}$ from 0 to 35 degrees and from 55 to 90 degrees. A quasi sinusoidal behavior can be seen for this nonlinear region. As such for the nonlinear region, Fourier series function can be utilized to represent the nonlinear region. $3^{\text {rd }}$ order Fourier series functions of cosine term were used to express the inductance profile for the nonlinear region. The nonlinear analytical model using $3^{\text {rd }}$ order Fourier series is described below:

$$
\begin{aligned}
L_{\text {nonlin }}(i, \theta) & =a_{0}(i)+a_{1}(i) \cos \left(\omega_{1} \theta\right)+a_{2}(i) \cos \left(2 \omega_{1} \theta\right) \\
& +a_{3}(i) \cos \left(3 \omega_{1} \theta\right)
\end{aligned}
$$

Where $\omega_{1}=\pi /\left(\theta_{\text {unal }}-\theta_{a l}\right) . \theta_{\text {unal }}$ and $\theta_{a l}$ are the rotor position at unaligned and aligned position which are at 90 degrees and 45 degrees respectively. The coefficients $a_{0}$, $a_{1}, a_{2}$ and $a_{3}$ can be found by applying eq (6). Eq (6) is presented with respect to the rotor position. As inductance behavior of SRM is dependent on rotor position as well as excitation current, the coefficients is the represented as function of excitation current. The coefficients is then represented as $2^{\text {nd }}$ Fourier series function with respect to the current as below:

$$
\begin{aligned}
a_{n}(i)= & A_{0 n}+A_{1 n} \sin \left(\omega_{2} i\right)+A_{2 n} \cos \left(\omega_{2} i\right) \\
& +A_{3 n} \sin \left(2 \omega_{2} i\right)+A_{4 n} \sin \left(2 \omega_{2} i\right)
\end{aligned}
$$

Where $\omega_{2}=\pi /\left(i_{\max }-i_{\min }\right) \quad i_{\max }$ and $i_{\min }$ is the maximum and minimum excitation current which are 900A and 9A respectively. Using eq (6) and (7), the coefficients are calculated and tabulated. Coefficient results are shown for rotor angle, $\theta_{r}$ from 0 to 35 in TABLE I and from 55 to 90 degree in TABLE II. Coefficient for $\theta_{r}$ from 55 to 90 is represented by the following notation, $B_{0 n}, B_{1 n}, B_{2 n}, B_{3 n}$ and $B_{4 n}$.

TABLE I COefFicient For $\theta_{r}$ From 0 to 35 Degrees

\begin{tabular}{|c|c|c|c|c|c|}
\hline $\mathbf{n}$ & $A_{0 n}$ & $A_{1 n}$ & $A_{2 n}$ & $A_{3 n}$ & $A_{4 n}$ \\
\hline 0 & $9.35 \mathrm{e}-5$ & $3.35 \mathrm{e}-5$ & $4.02 \mathrm{e}-5$ & $5.34 \mathrm{e}-6$ & $1.51 \mathrm{e}-5$ \\
\hline 1 & $4.53 \mathrm{e}-5$ & $3.65 \mathrm{e}-5$ & $3.04 \mathrm{e}-5$ & $8.47 \mathrm{e}-6$ & $1.31 \mathrm{e}-5$ \\
\hline 2 & $-4.18 \mathrm{e}-6$ & $-7.71 \mathrm{e}-6$ & $-3.61 \mathrm{e}-6$ & $-2.53 \mathrm{e}-7$ & $-5.24 \mathrm{e}-6$ \\
\hline 3 & $2.06 \mathrm{e}-6$ & $-1.53 \mathrm{e}-6$ & $5.27 \mathrm{e}-6$ & $-1.58 \mathrm{e}-6$ & $2.04 \mathrm{e}-6$ \\
\hline
\end{tabular}

TABLE II COEFFICIENT For $\theta_{r}$ From 55 to 90 DegRees

\begin{tabular}{|c|c|c|c|c|c|}
\hline $\mathbf{n}$ & $B_{0 n}$ & $B_{1 n}$ & $B_{2 n}$ & $B_{3 n}$ & $B_{4 n}$ \\
\hline 0 & $6.41 \mathrm{e}-5$ & $2.76 \mathrm{e}-5$ & $1.38 \mathrm{e}-5$ & $7.41 \mathrm{e}-6$ & $8.22 \mathrm{e}-6$ \\
\hline 1 & $7.06 \mathrm{e}-5$ & $2.70 \mathrm{e}-5$ & $5.96 \mathrm{e}-5$ & $-6.86 \mathrm{e}-7$ & $1.91 \mathrm{e}-5$ \\
\hline 2 & $-1.10 \mathrm{e}-5$ & $1.50 \mathrm{e}-5$ & $-1.81 \mathrm{e}-5$ & $9.29 \mathrm{e}-6$ & $-2.92 \mathrm{e}-6$ \\
\hline 3 & $1.07 \mathrm{e}-5$ & $-9.44 \mathrm{e}-6$ & $1.22 \mathrm{e}-5$ & $-4.19 \mathrm{e}-6$ & $-1.17 \mathrm{e}-6$ \\
\hline
\end{tabular}

\section{2) Linear Region Analytical Model}

Representing the linear region of the inductance is a lot more straight-forward in comparison to the nonlinear region. The linear region can be represented by just a simple first order polynomial. The analytical model for the linear region is presented as:

$$
L_{\text {lin }}(i, \theta)=P_{1} * \theta+P_{2}
$$

The calculated coefficients for the linear region are then calculated as $P_{1}=-1.161 e-22$ and $P_{2}=3.161 e-5$.With the analytical model defined for nonlinear and linear region of inductance defined, the piecewise analytical equation for inductance can then be expressed as the following expression:

$$
L(i, \theta)= \begin{cases}L_{\text {nonlin },} & 0 \leq \theta_{r} \leq 35 \\ L_{\text {lin }}, & 35 \leq \theta_{r} \leq 55 \\ L_{\text {nonlin, }} & 55 \leq \theta_{r} \leq 90\end{cases}
$$

Fig. 6 shows the inductance profile using the derived piecewise analytical model or inductance. The inductance model will be used as the base for modelling the flux linkage behavior.

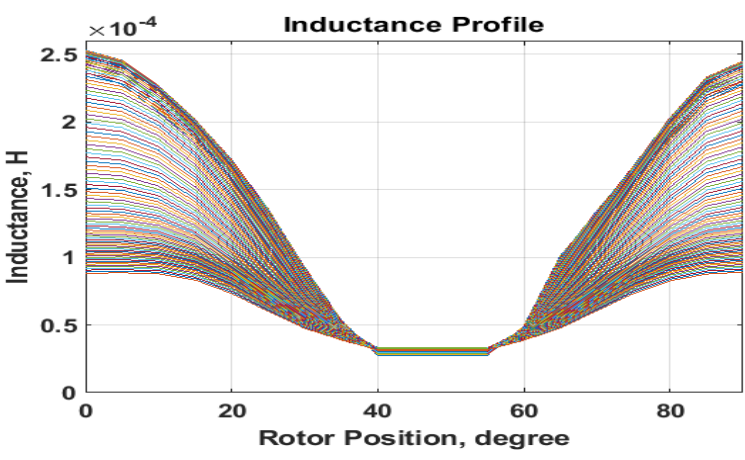

Fig. 6 Inductance Profile from Analytical Model

\section{B. Flux Linkage Modelling}

With the analytical model for inductance defined, deriving the analytical model for flux linkage is far simpler. Using the definition of flux linkage from eq (1), the analytical model defining flux linkage can be found. Replacing the piecewise inductance model from eq. (9) into eq (1), flux linkage for the excitation current and rotor position can be calculated. Fig. 7 shows the flux linkage behavior calculated using the analytical equation.

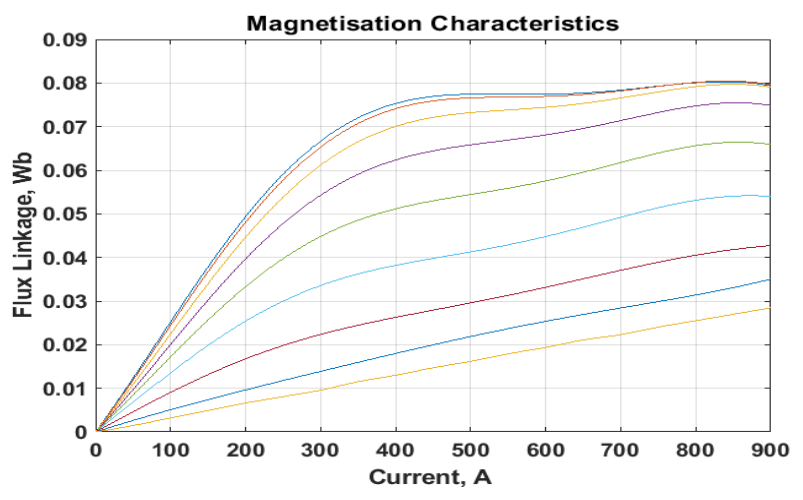

Fig. 7 Magnetization Characteristic from Analytical Model 


\section{ERROR ANALYSIS}

Fig. 6 and Fig. 7 presents the results of the analytical model of inductance and flux linkage. The results from the analytical model are then compared to measured values. Relative error is compared for inductance and flux linkage as shown in Fig. 8 and Fig. 9 low. Error is compared at 3 different inductance and flux linkage point. Calculated error values are then tabulated in TABLE III

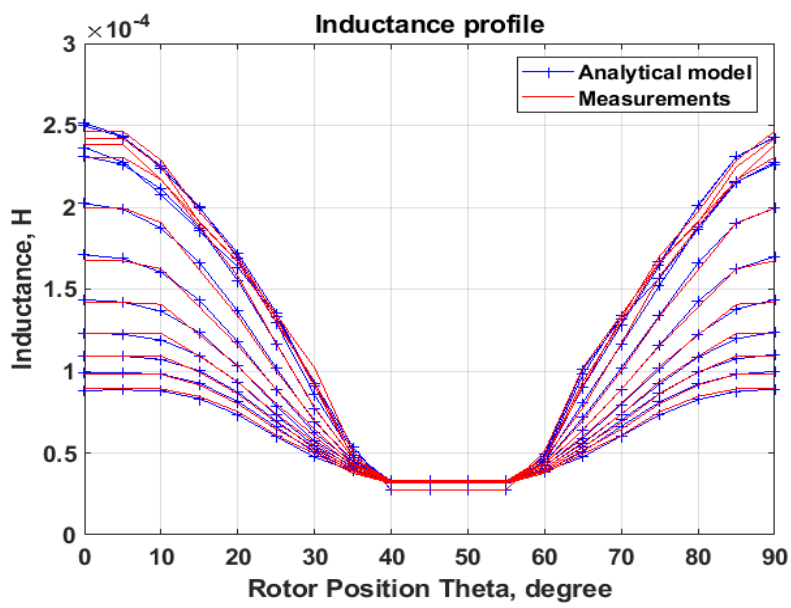

Fig. 8 Comparison of inductance profile

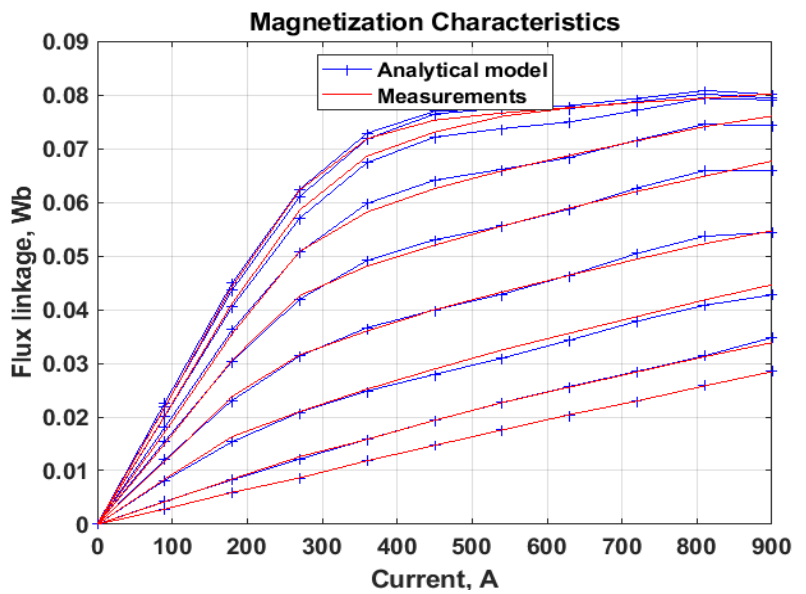

Fig. 9 Comparison of Magnetization Characteristics

TABLE III MEASURED ERROR DATA

\begin{tabular}{|c|c|c|c|}
\cline { 2 - 4 } \multicolumn{1}{c|}{} & \multicolumn{3}{c|}{ Measured Point } \\
\hline Inductance & $L\left(180 A, 20^{\circ}\right)$ & $L\left(180 A, 50^{\circ}\right)$ & $L\left(180 A, 80^{\circ}\right)$ \\
\hline $\begin{array}{c}\text { Relative } \\
\text { Error }\end{array}$ & $8.9474 \mathrm{e}-3 \%$ & $0 \%$ & $0.02 \%$ \\
\hline $\begin{array}{c}\text { Flux } \\
\text { Linkage }\end{array}$ & $\lambda\left(180 A, 10^{\circ}\right)$ & $\lambda\left(180 A, 25^{\circ}\right)$ & $\lambda\left(180 A, 45^{\circ}\right)$ \\
\hline $\begin{array}{c}\text { Relative } \\
\text { Error }\end{array}$ & $0.26 \%$ & $0.75 \%$ & $0.86 \%$ \\
\hline
\end{tabular}

The relative error tabulated in TABLE III shows small percentage of difference between the analytical model and the measured values. Error is particularly lower at the linear region as it is much simpler to obtain an accurate analytical model due to its linearity. By visual inspection of Fig. 6 and Fig. 7, it can be observed that the analytical is able to track the actual measured values rather closely. The values deviate at certain points due to the nonlinear behavior where the accuracy of the analytical modelling can be further improved. However, the piecewise analytical model presented for a specific SRM does provide a rather accurate analytical model that can be used for simulation and SRM control drives development.

\section{CONCLUSION}

In this paper, piecewise analytical modelling for a specific SRM is presented. The SRM used in this study is unlike conventional generic SRM due to its custom geometrical design. As such, the magnetic behavior of this SRM is rather unique and requires a specific analytical modelling solution. The piecewise modelling approach using the inductance profile presented provides a rather accurate model that can be used for further computer simulation studies using this model. The presented modelling technique approach can possibly be used for other specific custom designed SRM as well.

\section{ACKNOWLEDGEMENT}

This project has received funding from the Clean Sky 2 Joint Undertaking under the European Union's Horizon 2020 research and innovation program under grant agreement No 807081 .

\section{REFERENCES}

T. J. E. Miller, Electronic Control of Switched Reluctance Machines. Oxford: Newnes 2001.

B. Sarlioglu and C. T. Morris, "More Electric Aircraft: Review, Challenges, and Opportunities for Commercial Transport Aircraft," IEEE Transactions on Transportation Electrification, vol. 1, pp. 54-64, 2015.

P. Wheeler and S. Bozhko, "The More Electric Aircraft: Technology and challenges," IEEE Electrification Magazine, vol. 2, pp. 6-12, 2014.

X. D. Xue, K. W. E. Cheng, S. L. Ho, and K. F. Kwok, "Trigonometry-Based Numerical Method to Compute Nonlinear Magnetic Characteristics in Switched Reluctance Motors," IEEE Transactions on Magnetics, vol. 43, pp. 18451848, 2007.

I. Husain and S. A. Hossain, "Modeling, Simulation, and control of switched reluctance motor drives," IEEE Transactions on Industrial Electronics, vol. 52, pp. 16251634, 2005.

D. A. Torrey, X. Niu, and E. J. Unkauf, "Analytical modelling of variable-reluctance machine magnetisation characteristics," IEE Proceedings - Electric Power Applications, vol. 142, pp. 14-22, 1995.

A. Khalil and I. Husain, "A Fourier Series Generalized Geometry-Based Analytical Model of Switched Reluctance Machines," IEEE Transactions on Industry Applications, vol. 43, pp. 673-684, 2007.

H. Le-Huy and P. Brunelle, "A versatile nonlinear switched reluctance motor model in Simulink using realistic and analytical magnetization characteristics," in 31st Annual Conference of IEEE Industrial Electronics Society, 2005. IECON 2005., 2005, p. 6 pp.

X. D. Xue, K. W. E. Cheng, and S. L. Ho, "A self-training numerical method to calculate the magnetic characteristics for switched reluctance motor drives," IEEE Transactions on Magnetics, vol. 40, pp. 734-737, 2004.

M. R. X. Ding, C. I. Hill and S. Bozhko, "Analytical modelling approach for switched reluctance machines with deep saturation," presented at the 016 International Conference on Electrical Systems for Aircraft, Railway, Ship Propulsion and Road Vehicles \& International Transportation Electrification Conference (ESARS-ITEC), Toulouse, 2016. J. Borg Bartolo and C. Gerada, "Design and Modeling of a $45 \mathrm{~kW}$, Switched Reluctance Starter-Generator for a Regional Jet Application," 2014. 